\title{
Effects of exogenous melatonin on antioxidant system in leaves of kiwifruit seedlings under cadmium stress
}

\author{
Xiaojing Huang ${ }^{1, \mathrm{a}}$, Hui Xia ${ }^{1,2, \mathrm{~b}}$, Yanqiu Shen ${ }^{1, \mathrm{c}}$, Qin Wang ${ }^{1, \mathrm{~d}}$, Nengqin $\mathrm{Xu}^{1, \mathrm{e}}$, Zhi \\ Lei $^{1, f}$, Dong Liang ${ }^{1,2, g, *}$ \\ ${ }^{1}$ College of Horticulture, Sichuan Agricultural University, Chengdu, Sichuan, China \\ ${ }^{2}$ Institute of Pomology and Olericulture, Sichuan Agricultural University, Chengdu, Sichuan, China \\ a1301621709@qq.com, ${ }^{b}$ susanxia_2001@163.com, ${ }^{c} 517590097 @ q q . c o m$, \\ d2106846090@qq.com, ${ }^{\mathrm{e}} 1173604537 @ q q . c o m,{ }^{1} 1280195400 @ q q . c o m,{ }^{9}$ liangeast@sina.com
}

*Corresponding author. Xiaojing Huang and Hui Xia contributed equally to this work.

Keywords: Kiwifruit; Exogenous melatonin; Cadmium stress; Antioxidant system

Abstract: Using one-year-old wild Actinidia deliciosa as the experimental material, effect of melatonin (MT) on the antioxidant system under heavy metal Cd stress was studied. The results showed that after $\mathrm{Cd}$ stress treatment, the relative electrical conductivity, MDA content, proline content, soluble protein content, $\mathrm{H}_{2} \mathrm{O}_{2}$ content and protection enzyme activity of kiwifruit seedlings leaves increased first and then decreased than those of control (CK). However, pretreatment with MT irrigatiing root effectively alleviated the kiwi membrane lipid peroxidation, reduced the relative level of membrane permeability, MDA content, $\mathrm{H}_{2} \mathrm{O}_{2}$ content, at the same time significantly increased the proline content, soluble protein content, improved the activity of protective enzyme, suggesting that MT can availably reduce the harm of Cd stress, improve the tolerance to $\mathrm{Cd}$ stress of kiwifruit seedling.

\section{Introduction}

With the development of industrialization and transportation industry, the phenomenon of heavy metal pollution in soil was very serious [1]. Cd was a major toxicant in the soil of heavy metal pollutants, according to statistics, China's Cd pollution of soil area has reached 200,000 $\mathrm{km}^{2}$ [2]. Kiwifruit growth needs trace amounts of heavy metals, but beyond a certain limit in the soil will produce toxic effects on fruit trees and even lead to death [3]. Melatonin (MT), a neuroendocrine hormone secreted by the mammalian pineal gland, with antioxidant activity and is a highly impactful free radical scavenger that can effectively remove $\mathrm{OH}^{-}, \mathrm{O}_{2}{ }^{-}$, peroxy radical, $\mathrm{OONO}^{-}$, and ${ }^{1} \mathrm{O}_{2}[4,5]$. MT in this way can improve plant resistance to stress $[6,7,8,9,10]$. In this study, wild Actinidia deliciosa seedlings were used to study the effects of exogenous melatonin on antioxidant system in leaves of kiwifruit seedlings under cadmium stress. The results will helpful to use rational MT to solve heavy metal stress issues in the kiwi cultivation and provide a theoretical basis on anti-heavy metals stress of kiwi breeding.

\section{Materials and Methods}

Materials and Treatment. Seeds of wild Actinidia deliciosa was collected from Qinling, Shaanxi Province, China in September 2015, and were placed in sand for 50 days at $4^{\circ} \mathrm{C}$ and $60-70 \%$ relative humidity in winter.kept at $4{ }^{\circ} \mathrm{C}$ for untill March, 2016. After variable temperature treatment at $4{ }^{\circ} \mathrm{C} 16 \mathrm{~h}$, $24^{\circ} \mathrm{C} 8 \mathrm{~h}$ for two weeks, seeds were placed at $25^{\circ} \mathrm{C}$ for $10-15$ days to germinate. We began watering the seedlings at 2-day intervals with 1/2 Hoagland's nutrient solution at the two-true-leaf stage $(\mathrm{pH}$ adjusted to $6.5 \pm 0.1$ with diluted $\mathrm{HCl}$ or $\mathrm{NaOH}$ ).

When grown up with 9-10 true leaves, seedling was irrigated with $0.1 \mathrm{~mol} \cdot \mathrm{L}-1 \mathrm{MT}$ solution for five times, two days once. Afterwards, seedlings were treated with $5 \mathrm{mg} \cdot \mathrm{L}^{-1}\left(\mathrm{CdCl}_{2}\right)$ for 15 days, irrigated once every two days. Middle leaves (seven to nine per plant) were sampled after 0, 3, 6, 9, and 12d. All collected tissues were immediately frozen in liquid nitrogen and stored at $-80^{\circ} \mathrm{C}$. 
Enzymes Assay and Indicator Determintion. Relative electric conductivity, free proline, MDA and antioxidant enzymes (SOD, POD, CAT) content determination method adopted Li Hesheng, soluble protein content determination of the coomassie brilliant blue $\mathrm{G}-250$ staining method, $\mathrm{H}_{2} \mathrm{O}_{2}$ content determination method adopts Lin Zhi-fang [11,12].

Data Analysis .Analysis of variance was performed using the SPSS software (SPSS, Inc., Chicago, IL, USA). Each treatment was replicated three times. Significant differences were detected using Duncan's test at the $P<0.05$ level.

\section{Results and Discussion}

MDA Content and $\mathrm{H}_{2} \mathrm{O}_{2}$ Content. After irrigating with Cd solution, MDA content in leaves of kiwifruit seedling was increased first and peaked at the $6 \mathrm{~d}$ with $21.1 \mathrm{nmol} \cdot \mathrm{g}^{-1} \mathrm{FW}$, and then decreased towards, which were significant higher than those in CK all over the time. However, when pretreated with MT, the MDA content of seedling significantly decreased when compared with CK, by $32.24 \%$ at 6d (Figure. 1A). The $\mathrm{H}_{2} \mathrm{O}_{2}$ content in the leaves of $\mathrm{Cd}$ and $\mathrm{MT}+\mathrm{Cd}$ treatments increased significantly from 3 to 6 days. However, from 6 to $9 d$, the $\mathrm{H}_{2} \mathrm{O}_{2}$ content in MT+Cd treatment began to decrease, but treatment of $\mathrm{Cd}$ still on the rise and higher than that of $\mathrm{CK}$; From 9 and $12 \mathrm{~d}$, the $\mathrm{H}_{2} \mathrm{O}_{2}$ content in $\mathrm{MT}+\mathrm{Cd}$ treatment was significantly lower than that of Cd treatment, decreased by $41.45 \%$ and $51.99 \%$, respectively. At $12 \mathrm{~d}$, the $\mathrm{H}_{2} \mathrm{O}_{2}$ content of $\mathrm{MT}+\mathrm{Cd}$ treatment was lower than that of $\mathrm{CK}$ (Figure. 1B).
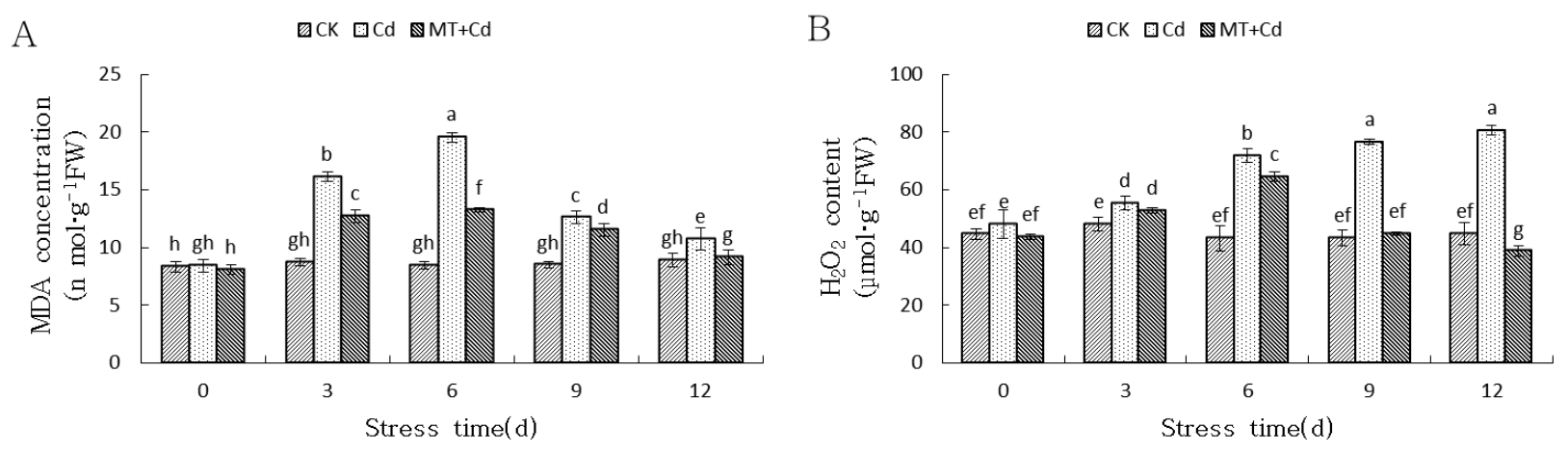

Figure. 1 Effects of exogenous melatonin on MDA content (A) and $\mathrm{H}_{2} \mathrm{O}_{2}$ content (B) in kiwifruit under Cd stress

Note: Data with the different letters indicate the difference is significant $(\mathrm{P}<0.05)$.

Relative Conductivity, Soluble Protein and Free Proline Content. Under Cd stress, the relative electrical conductivity of leaves of kiwifruit seedling was increased at first 6 days, when compared with CK increased by $105.43 \%$ and then decreased towards. However, when pretreated with MT, the relative electrical of seedling significantly decreased when compared with Cd, by $20.42 \%$ at $6 \mathrm{~d}$ (Figure. 2A). The soluble protein content in the leaves of $\mathrm{Cd}$ and $\mathrm{MT}+\mathrm{Cd}$ treatments showed an upward trend and peaked at $12 \mathrm{~d}$,increased significantly from 6 to $9 \mathrm{~d}$. However, the soluble protein content in $\mathrm{MT}+\mathrm{Cd}$ treatment higher than those in $\mathrm{Cd}$ all over the time (Figure. 2B). The proline content in the leaves of $\mathrm{Cd}$ and MT+Cd treatments increased significantly from 3 to 6 days and peaked at $6 \mathrm{~d}$, when compared with CK increased by $122.70 \%$ and $195.99 \%$ and then decreased towards. But The proline content in the leaves of $\mathrm{MT}+\mathrm{Cd}$ treatment higher than that of $\mathrm{Cd}$ all the time (Figure. $2 \mathrm{C}$ ). 

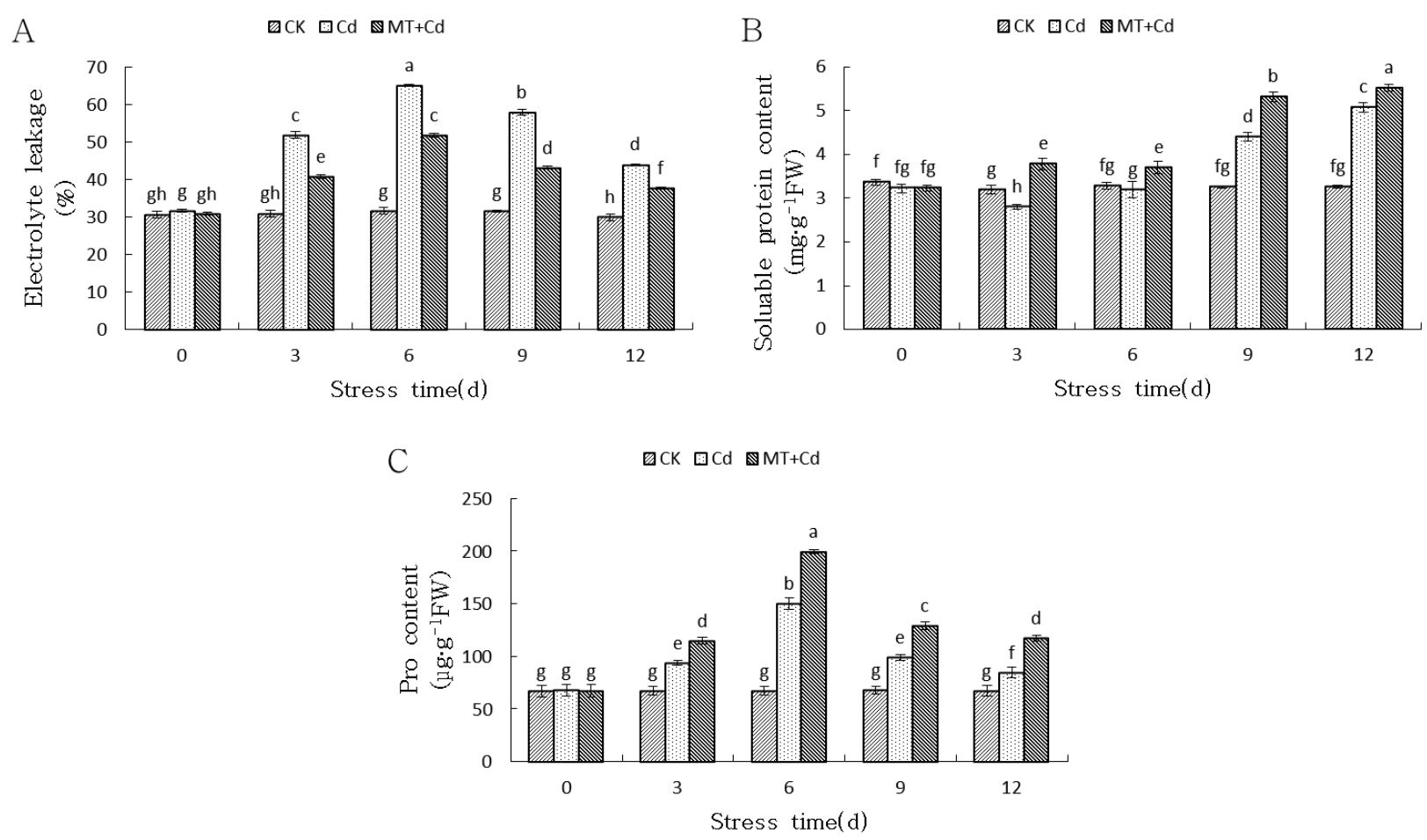

Figure. 2 Effects of exogenous melatonin on relative conductivity(A), soluble protein content(B) and free proline content $(\mathrm{C})$ in kiwifruit under $\mathrm{Cd}$ stress

Note: Data with the different letters indicate the difference is significant $(\mathrm{P}<0.05)$
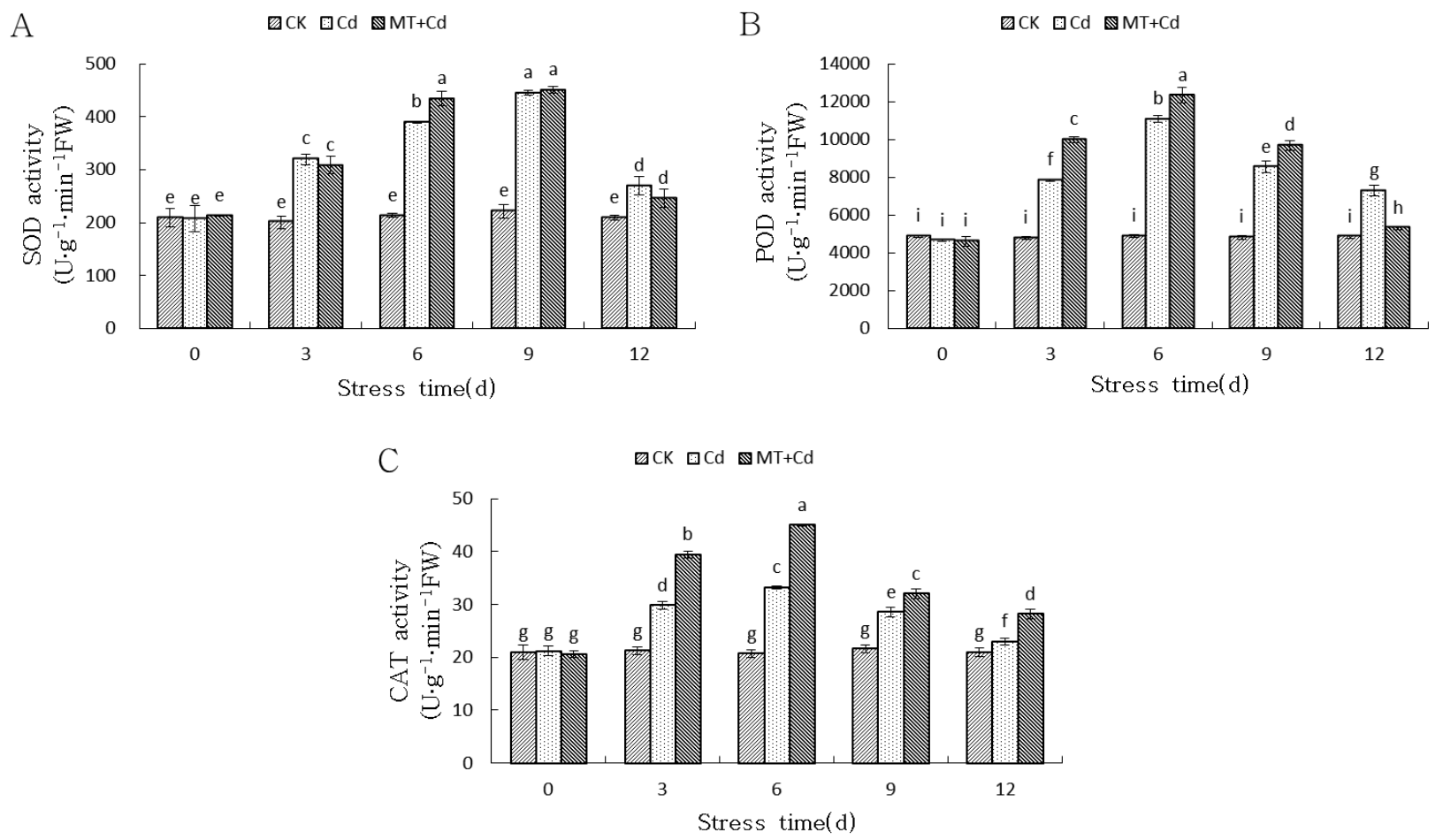

Figure.3 Effects of exogenous Melatonin on $\operatorname{SOD}(\mathrm{A}), \operatorname{POD}(\mathrm{B}), \mathrm{CAT}(\mathrm{C})$ activity in kiwifruit under Cd stress

Note: Data with the different letters indicate the difference is significant $(\mathrm{P}<0.05)$.

SOD, POD, and CAT Activity. SOD activity in the leaves of $\mathrm{Cd}$ and $\mathrm{MT}+\mathrm{Cd}$ treatments was increased first and peaked at $9 \mathrm{~d}$ and then decreased towards. When compared with $\mathrm{Cd}$, the SOD activity in the leaves of MT+Cd treatment increased significantly, by $11.60 \%$ at $6 \mathrm{~d}$ (Figure. 3A). After irrigating with $\mathrm{Cd}$ solution, POD activity in leaves of kiwifruit seedling was increased first and peaked 
at the $6 \mathrm{~d}$ with $11093.33 \mathrm{U} \cdot \mathrm{g}^{-1} \cdot \mathrm{min}^{-1} \mathrm{FW}$, and then decreased towards. However, when pretreated with MT, the POD activity of seedling significantly increased when compared with Cd from 3 to $9 \mathrm{~d}$ (Figure. 3B). Under Cd stress, the CAT activity of leaves of kiwifruit seedling was increased first and peaked at the $6 \mathrm{~d}$ with $33.18 \mathrm{U} \cdot \mathrm{g}^{-1} \cdot \mathrm{min}^{-1} \mathrm{FW}$, and then decreased towards, which were significant higher than those in CK all over the time. when pretreated with MT, the CAT activity of seedling significantly increased, when compared with $\mathrm{Cd}$ treatment, by $35.59 \%$ at $6 \mathrm{~d}$, and then decreased towards, which were significant higher than those in Cd all over the time (Figure. $3 \mathrm{C}$ ).

\section{Conclusions}

To date, studies on MT are mostly developed for medical drugs to delay human aging. The results of this study show that the antioxidant function of MT can also promote the resistance of kiwifruit seedlings. The optimum concentration of MT could decrease the relative conductivity, increase free proline and soluble protein content, effectively relieve the accumulation of $\mathrm{H}_{2} \mathrm{O}_{2}$ and MDA in the plant, increase SOD, POD, CAT activity, maintain normal balance of active oxygen metabolism, protect the normal physiological function of the membrane, inhibit membrane lipid peroxidation to improve the adaptability of kiwi to cadmium stress.

\section{References}

[1] Clemens S: Biochimie Vol. 88 (2006), p. 1710.

[2] Lie Ran and Hesheng Li: Journal of Chongqing Academy of Arts and Sciences: Natural Science Edition Vol. 30 (2011), p. 69. (in Chinese)

[3] Lisong Chen and Xinghui Liu: Journal of Fujian Agriculture And Forestry University (Natural Science Edition) Vol. 30 (2001), p. 467. (in Chinese)

[4] Tilden AR, Becker MA and Amma LL: Journal of Pineal Research Vol. 22 (1997), p. 102.

[5] Tan DX, Chen LD and Poeggeler B: Endocrinol J Vol. 1 (1993), p. 58.

[6] Xiangdong Xu, Yan Sun and Bo Sun: Journal of Applied Ecology Vol. 21 (2010), p. 1299. (in Chinese)

[7] Guiyou Zhang, Ping Li and Yaoren Dai: Chinese Bulletin of Botany Vol. 22 (2005), p. 558. (in Chinese)

[8] Posmyk MM, KURAN H and MARCINIAK K: Journal of Pineal Reseach Vol.45 (2008), p. 29.

[9] Wang P, Sun X and Li C: Journal of Pineal Research Vol.54 (2013), p. 301.

[10] Li C, Wang P and Wei Z: Journal of Pineal Research Vol.53 (2012), p. 304.

[11] Li H: Principle and technology of plant physiology and biochemistry experiment. (Higher Education Press, Beijing 2000)

[12] Zhifang Lin, Shuangshun Li and Guizhu Lin: Journal of Plant Physiology (1988), p. 24. (in Chinese) 